\title{
Designing pension solutions in the new defined contribution world
}

Received: 4th November, 2002

\section{Dick Strattan}

joined Mercer in 1997 and is a worldwide partner. He has played a key role in coordinating UK strategic benefits consulting work for Mercer's clients and has personally provided such advice to a number of major clients. Prior to joining Mercer, Dick spent 20 years as a partner of Clay \& Partners. Dick has been spearheading Mercer's consulting on stakeholder pensions and on the new defined contribution (DC) playing field in the UK. He is a regular speaker at National Association of Pension Funds (NAPF) and other keynote industry conferences. He writes regularly in the pensions and national press.

\begin{abstract}
This paper considers the very different market backcloth against which company pension schemes now have to be designed and implemented. It starts by analysing what companies and employees are ideally looking for. Predictability and manageable levels of cost are key for companies. For employees, a 'one-size-fits-all' solution is no longer appropriate, but they desperately need high quality help and education to guide them through the stormy pension seas.

After then looking at some of the key elements of the new market backcloth (including means-tested benefits, government interference, flexible retirement and segmentation of the workforce) the paper briefly looks at some possible solutions. These range from halfway houses (between final salary and full-scale DC), to different types of DC designs and also to non-pension solutions to retirement saving.

The key conclusions are that most employees are very concerned and confused about pensions (and other financial products). As companies increasingly move towards DC schemes (and also offer non-pension opportunities for retirement saving, such as share plans), employees will need help and education to plan their retirement saving. The only realistic way to deliver such help is via employers, but the current legislative, regulatory and tax environments can act to discourage companies providing such help.
\end{abstract}

Keywords: defined contribution $(D C)$ pensions; pension scheme design; pension reform; employee education; over-regulation of pensions

Dick Strattan William M Mercer Ltd Telford House, 14 Tothill Street, London SW1H 9NB, UK.

Tel: $+44(0) 207222$ 6140; Fax: +44 (0)20 7222 6140; e-mail:

dick.strattan@mercer.com

\section{Introduction}

The cost to companies of providing employees with pensions linked to pay (defined benefit or 'DB' schemes) has been rising rapidly, as have the business risks imposed by such schemes. Many companies are therefore taking steps to stem future costs and risks by closing DB schemes to new employees, and in some cases closing them to future service of existing employees. They are usually putting in defined contribution (DC) schemes instead.

This paper considers what companies and employees are looking for in this new scenario, examines the backcloth against which solutions must be framed, and looks briefly at some possible answers. 
One key conclusion is that a one-size-fits-all pension scheme design no longer works. This is partly because of the huge diversity of personal and financial situations faced by individuals. But it is also due to the confusing array of pension and saving products available, and the very substantial level of 'as-of-right' and 'means-tested' benefits provided by the State. Even for those on modest incomes, these state benefits can be very substantial, and companies need to factor them in when designing pension solutions for employees.

As companies move toward more diverse solutions, their already confused workforces will need sensible and well-founded help, education and advice in order to navigate their way through the options open to them.

\section{What are companies looking for?}

In this ever more transparent world, companies will find it increasingly difficult to hide the true costs and exposures which mature DB schemes create. Also, there is increasing emphasis on culture within companies, and on using pay and benefits to align employee behaviour to corporate objectives. So companies are typically seeking the following:

- a known level of cashflow and company accounting costs each year

- no timebombs from past benefit commitments

- maximum 'bang for the buck' from pay and benefits spend

- pensions to be consistent with wider business objectives and reward programmes

- happy, well-motivated employees, aligned to act consistently with company aims

- to avoid regulatory/compliance breaches.

\section{But what about employees?}

Many employees are seeing their access to DB schemes closed off, particularly when they move jobs. Under DC schemes, risk is largely transferred from company to employee. As already mentioned, the vast array of different pension and savings vehicles available, combined with complex and (for the lower paid) generous state benefits, means many individuals are very confused. Pensions feature regularly in the national and local press, and these days it is rarely in a good light. So employees are looking for the following:

- high quality help, education and advice from someone they can trust and who is not trying to sell them something they do not need - solutions that match their own specific financial and personal circumstances and that reflect their own preferences and plans for the future.

It is a very fast-changing world, and those with ' 2.4 children' and their original spouse are now in a minority. Increasingly, individuals are inheriting property from their parents and grandparents. Children of the better off may get Stakeholder pensions set up for them, and have substantial savings as a result by age 18 .

It is also likely that the newer generations will be much keener to claim all their 'rights' from the State and so the take-up percentage of means-tested benefits is likely to rise. Again, individuals will want help to achieve this and to plan ahead.

\section{Pensions design: the backcloth}

Having identified some of the things companies and employees are looking for (and the priorities will differ greatly 
from company to company), there are a number of things we need to be aware of before ploughing into the design itself.

\section{Means-tested benefits}

Because of the way these currently operate, there is a positive disincentive for many lower/moderate earners to save for retirement. This is particularly true for those in rented accommodation where means-tested entitlement from housing benefit plus income support and council tax benefit would effectively be wiped out by any private pension savings. The Chancellor's new pension credit does surprisingly little to alleviate this situation.

Many employers providing 1/60ths pensions to low-paid and part-time employees are arguably pouring their money away. The big 'if' here is whether currently employees can plan ahead on this basis, or will the benefits and rules be changed by future governments?

\section{Government interference}

Before the 1970s, pensions were a quiet backwater and there was relatively little meddling by the State. Since then, successive layers of legislation, complexity and red tape have been piled on schemes. Some of the most damaging ones placed retrospective cost increases on companies for pensions they thought they had already paid for. The two main culprits here are removal of the ACT tax credit by the Chancellor, and the equalisation nightmare from the European Court of Justice.

Future changes of this kind need to be anticipated. One likely change, in the author's view, is that this or a future government will make pension contributions by companies mandatory for all employees.
But we also have Pickering, Sandler and the Pensions Taxation reviews going on, and any major design changes implemented prior to knowing the final outcome of all three might prove badly founded.

\section{Blurry retirement}

The increased diversity of workforces is extending to retirement situations. Rarely now is retirement a one-off event, with the gold watch awarded at age 65. Many people now pursue second careers, take up consulting roles or work part time, instead of retiring.

Financial pressures on pension schemes and increasing life expectancy mean many people will need to retire later (and indeed state pensions may get moved towards age 70 too).

Two other thoughts here are worth considering:

- Is throwing money at pensioners the right answer, or do they need solutions to their ageing problems instead (eg, access to carers, medical attention, sheltered accommodation etc)?

- Company pensions have to be increased each year by statute, and this greatly increases the cost. However, as people age in retirement they actually tend to spend less as they become less active. Is this not a bad mismatch?

\section{Trust v. contract-based pensions}

The arrival of Stakeholder pensions led to insurance and investment providers totally re-engineering their business models. Some got this right and can now provide personal, Stakeholder and company pensions at very low cost. When companies are designing pension schemes, they need to factor this in and 
then choose the best solution for their own workforce.

Because of the above change in the cost equation, the right choice between a company 'trust-based' scheme and an insured contract-based scheme (eg, Stakeholder) often comes down to the desired level of interaction with employees. For employers who want little involvement and interaction, a personal pension or Stakeholder route will often be best. For those who want more control and interaction, the trust-based route will probably work better.

\section{Segmentation}

A key decision for companies will be whether to segment their workforce and tailor pension solutions accordingly. Some may still want to offer a one-size-fits-all approach because of their culture/philosophy. However, the diversity already referred to means such an approach is likely to represent a poor quality of spend by the employer and poor quality of outcome for employees. Perhaps by having a flexible range of options, and by providing help and education for employees (to choose the best options for their own situation), a more acceptable compromise can be achieved.

\section{Contracting in or out}

Currently most large DB schemes (and many DC schemes) are contracted out of the State's top up pensions (formerly SERPS and now the State Second Pension). This has become increasingly poor value for employers and employees, and most new DC schemes are likely to be contracted in (or, to be technically correct, 'not contracted out'). By contracting out of the State Second Pension, employees are giving up a defined benefit from the State in return for government payments into a DC scheme. Where a company does 'contract in', individual employees who want to contract out can still do so by going direct to an insurance company.

\section{Some possible pension solutions}

The key messages so far are:

- an appreciation is needed of what the company and its employees want, and what their priorities are.

- a good understanding of the pensions backcloth is needed, to avoid unworkable and unsustainable solutions.

- solutions will need to be flexible enough to fit a diverse workforce with very different personal and financial situations.

Below, in brief outline, are some of the solutions that might be used in practice.

\section{Middle-ground solutions}

Rather than switch fully to DC, it may be appropriate to consider 'cheaper' DB arrangements such as reduced accrual rate or career average revalued (CARE) schemes. These normally link accruing pensions to price inflation rather than earnings inflation.

\section{Tax-free cash only}

For those caught by the meanstesting/poverty trap, a tax-free cash only scheme based on 3/80ths of salary for each year can be a very good benefit, as they can spend the money and then still claim full state benefits later.

\section{DC solutions}

These can be tailored according to the company's objectives and philosophy. For 
example, age-related contributions can reflect the higher cost of providing each $\mathcal{L}_{1}$ of pension as people get nearer to retirement.

Service-related contributions can be used to tie in longer serving employees.

Performance-related contributions can be used to reward those who achieve defined company objectives. Matching of employee contributions can be used by the employer to encourage employees to save more themselves. Matching can be set at differing levels (eg 1:1, 2:1) to achieve different objectives.

\section{Non-pension solutions}

Although higher risk, All Employee Share Plans (AESPs) are usually more tax-effective than pension plans.

Employers can facilitate these and other options in order to give employees more choice about how they build up their retirement assets.

\section{Conclusion}

Legislation, cost and risk are driving companies away from $\mathrm{DB}$ and towards DC. This is a worldwide rather than merely UK trend. As employees are asked to take the risk associated with DC, they are going to need help, education and advice in order to survive and to avoid shocks and surprises. The only realistic way to deliver such help is via employers. This is likely to happen only if the regulatory and tax environments encourage employers to get involved, and at the moment they lead employers away from such involvement. 